\title{
Calculation and Improvement of Complex Mechanical Properties of the Mega Arch Dam under Multiple Loads Based on Finite Element Methods
}

\author{
Chenghua Fu $\mathbb{D}^{1}{ }^{1}$ Hongbo Zhou, ${ }^{2}$ and Yanfang Pan ${ }^{3}$ \\ ${ }^{1}$ Key Laboratory of Fluid and Power Machinery, Ministry of Education, Xihua University, Chengdu, Sichuan, China \\ ${ }^{2}$ The Yalong River Hydropower Development Co. Ltd., Chengdu, Sichuan, China \\ ${ }^{3}$ China Electric Construction Group Chengdu Survey and Design Research Institute Co. Ltd., Chengdu, Sichuan, China \\ Correspondence should be addressed to Chenghua Fu; fuchenghua@sina.com
}

Received 26 May 2018; Accepted 25 July 2018; Published 19 August 2018

Academic Editor: Changzhi Wu

Copyright ( $) 2018$ Chenghua Fu et al. This is an open access article distributed under the Creative Commons Attribution License, which permits unrestricted use, distribution, and reproduction in any medium, provided the original work is properly cited.

\begin{abstract}
Researches on dynamic responses of the arch dam under seismic waves were not systematic and perfect enough in published papers. They rarely proposed measures to improve the antiseismic performance of the arch dam under seismic waves. Based on the finite element method, this paper completed a systematic and perfect research on stress and damage of the arch dam under seismic waves and proposed an effective measure to improve the antiseismic performance. The computed results of the improved arch dam were compared with the original one. Results proved that improved effects are obvious. In addition, damage stabilization value of the improved arch dam was 0.47 , while the original one was 0.13 . Obviously, the safety of the improved arch dam under the same loads was higher. Damage of the improved arch dam was increased by stages. It took about $3 \mathrm{~s}$ from zero damage to the complete damage, while the time was about only $1.3 \mathrm{~s}$ for the original one. Obviously, the antidamage capability of the improved arch dam was better. The improved measure proposed in this paper is very effective. This paper provides one reference for studying and improving the antiseismic performance of the arch dam.
\end{abstract}

\section{Introduction}

Arch dam is a dam type commonly seen in water conservancy projects. It is characterized in saving of materials, extra bearing capacity, full use of material intensity, and so forth [1-5]. When dam rock masses on two shores are stiff enough, the safety of arch dam will be higher than other concrete dams. Arch dam is a spatial shell structure with joint effects of a horizontal arch ring and vertical beams, wherein an arc shape raising to the upstream part is formed in the horizontal direction. The profile of the crown cantilever of a singlecurvature arch dam is vertical. The profile of the crown cantilever of a double-curvature arch dam is bent towards the upstream direction. The arch dam structure responds to earthquakes in a very complicated manner. When it is damaged by earthquake disasters, serious secondary disasters will be caused. Hence, it is quite useful and practical to research dynamic characteristics of the arch dam structure under dynamic loads through dynamic analysis of the arch dam. During dynamic response analysis of the arch dam, the interaction mechanism of the foundation and structure is very complicated, while the calculation amount is large, so experimental testing could hardly be achieved. Actual site materials could hardly be obtained, so computation results obtained by different computation models are quite different. This is also a basic problem to be solved in antiseismic response analysis of arch dams.

At present, a lot of researches have been conducted on dynamic responses of arch dams under earthquake effects. Based on the theoretical basis of viscoelastic artificial boundaries and in combination with the seismic motion input method of wave field decomposition, Li et al. [6] used the parameterized language APDL of ANSYS software to compile a program which simulates viscoelastic artificial boundaries and seismic load input. Aiming at a roller compacted concrete arch dam, a finite element model with joint effects 
of "reservoir water-arch dam foundation" was established, and effects of different foundation models on dynamic responses of the arc dam were computed. Du [7] could apply the proportional boundary finite element method to simulate easily the advantages of a heterogeneous infinite field and research effects of a heterogeneous infinite foundation on dynamic responses of the double-curvature high arch dams. The arch dam, foundation, and reservoir water could be simulated by the proportional boundary finite element method, so the large calculation amount could be reduced. In order to research variation rules of arch dam under seismic loads, Li and Yang [8] conducted modal analysis and antiseismic dynamic analysis of the arch dam based on ANSYS, finding that it is necessary to pay more attention to the dam abutment which is a tensile weak part under seismic loads; the variation rules of reliability of the middle part of the upstream dam face of the arch dam are complicated, while the index does not decrease purely. This result provides theoretical support for dynamic design and reinforcement measures of the arch dam. In order to discuss effects of different reservoir water models on dynamic characteristics of the arch dam structure, Zhang et al. [9] applied engineering cases and established an added mass model and a fluid-solid coupling model for dynamic characteristics analysis. Results show that dynamic characteristics of the structure could be reflected by both models. Based on contact of the nonlinear finite element model, Chen [10] used an added mass model, a compressible fluid finite element model, and an incompressible fluid finite element model for the reservoir water so as to compute dynamic responses of the dam body under the normal pool level and running of the low level. Results show that accuracy of arch dam dynamic responses computed with the reservoir water model was high. Li et al. [11] applied the Lagrange discontinuous deformation analysis (LDDA) to simulate horizontal cracks of the arch dam, used viscoelastic boundaries as the energy absorbance boundaries to simulate the infinite foundation radiation damp, established a seismic free field input model of the arch dam, and conducted dynamic response analysis of the arch dam. Alembagheri and Ghaemian [12] assessed the damage of concrete arch dams through nonlinear incremental dynamic analysis of a typical arch dam. In this study, the Morrow Point arch dam is subjected to a set of 12 three-component earthquakes each scaled to 12 increasing intensity levels. Sevim et al. [13] investigated the water level effects on the dynamic characteristics of a prototype arch dam model using ambient vibration testing.

However, in these reports, researches on dynamic responses of the arch dam under seismic effects were not systematic and perfect enough. They rarely proposed measures to improve antiseismic performance of the arch dam under the seismic effect. Based on the finite element method, the paper conducts systematic and perfect research of stress displacement and damage of the arch dam under seismic effects and proposes an effective measure to improve antiseismic performance of the arch dam. Improvement effects are obvious. The paper provides reference for research and improvement of antiseismic performance of the arch dam.

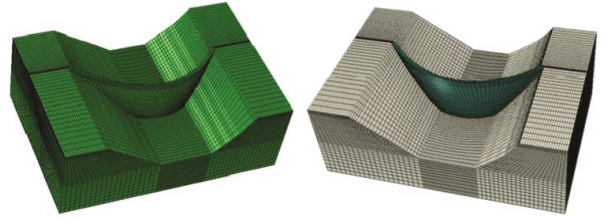

FIgURE 1: Finite element model of the arch dam.

\section{Finite Element Model of Arch Dam}

In the research of this paper, the dam height is $H=56 \mathrm{~m}$, and the upstream water depth is $54.5 \mathrm{~m}$. Finite element modeling scope and coordinate axis directions: 1.4 multiples and 2.4 multiples of the dam heights, were selected along the river towards the upstream and downstream directions; the 1multiple dam height was selected in the left and right crossriver directions; the 1-multiple dam height was selected in the vertical direction under the dam bottom. As for the coordinate axis system, the direction along the river is $y$-axis, and the downstream-to-upstream direction is positive; the direction cross the river is $x$-axis, and the right bank-to-left back direction is positive; the vertical direction is $z$-axis, and the vertical upward direction is positive. The dam body is simplified as follows: surface holes, middle holes, elevator shafts, various galleries, and other structures of the arch dam were not taken into account; the dam body is shaped like a continuous double-curvature arc; the basic rock is a mass-less elastic body; the seismic dynamic water pressure is converted to the mass attached to the upstream dam face node corresponding to the unit seismic acceleration; mass elements were added at corresponding nodes. During modeling of gravity dam, 4-node planar units were used as an auxiliary tool for mesh formation, while 6-node block units were used in practical computation. Specific course is as follows: 4-node planar units were firstly used to form a dam body perpendicular to the axis as well as the basic two-dimensional cross section; then, the "stretching" function of software was used to "stretch" them to upstream and downstream directions; during the "stretching," relative positions of the dam body and basic rock were gradually adjusted, so block units of the dam body and basic rock were formed; further, a three-dimensional overall model (containing the foundation) was formed. After units of the model were generated, the software would automatically detect differentiation of the units [14-17]. Linkage rod constraints existed on left and right boundaries, upstream and downstream boundaries, and dam foundation bottom. Finally, the obtained finite element of the arch dam is shown in Figure 1. As for the dam body, the elasticity modulus is $2.55 \mathrm{GPa}$; the Poisson's ratio is 0.167 ; the density is $2400 \mathrm{~kg} / \mathrm{m}^{3}$; the elastic modulus of basic rock is $18 \mathrm{GPa}$; the Poisson's ratio is 0.20 ; and density is $1 e-5 \mathrm{~kg} / \mathrm{m}^{3}$.

The finite element model was used to compute inherent frequencies of the arch dam under an empty-reservoir state and a full-reservoir state. Results are shown in Table 1. It is shown in Table 1 that the natural vibration frequency of the arch dam was low; under the empty-reservoir working condition, frequencies of first 7 orders only ranged within 
TABLE 1: Natural vibration frequencies of arch dam under emptyreservoir and full-reservoir conditions.

\begin{tabular}{lcc}
\hline $\begin{array}{l}\text { Number of } \\
\text { modal order }\end{array}$ & $\begin{array}{c}\text { Natural vibration } \\
\text { frequency at } \\
\text { empty-reservoir } \\
\text { state (Hz) }\end{array}$ & $\begin{array}{c}\text { Natural vibration } \\
\text { frequency at } \\
\text { full-reservoir } \\
\text { state (Hz) }\end{array}$ \\
\hline 1 & 3.3541 & 2.4486 \\
2 & 4.0612 & 2.8589 \\
3 & 4.9001 & 3.5555 \\
4 & 7.1724 & 5.4080 \\
5 & 8.3217 & 5.9904 \\
6 & 8.4571 & 6.7308 \\
7 & 8.9459 & 6.9262 \\
\hline
\end{tabular}

$3.3541 \mathrm{~Hz} \sim 8.9459 \mathrm{~Hz}$; and under the full-reservoir working condition, frequencies of the first 7 orders ranged within $2.4486 \mathrm{~Hz} \sim 6.9262 \mathrm{~Hz}$. This result depends on rigidity and mass of the arch dam. Large rigidity of concrete and large mass of the whole concrete arch dam directly lead to the characteristic of low frequency in the concrete high arch dam. At the empty-reservoir state, the natural vibration base frequency of the dam body was $3.3541 \mathrm{~Hz}$ and the natural vibration base frequency under the full-reservoir state was $2.4486 \mathrm{~Hz}$, which decreased by $26.99 \%$ in comparison with the empty-reservoir state. This is because, in comparison with the empty-reservoir state, water loads under the fullreservoir working condition were applied to the watermeeting face of dam body in the form of added mass. As a result, mass of the dam body increased. However, the rigidity of the arch dam is the same. Natural vibration frequency of the structure is related to mass and rigidity of the structure, but it is in inverse ratio to mass, so the natural vibration frequency decreased.

Vibration modes of the arch dam at first 7 orders were extracted, as shown in Figure 2. It is shown in Figure 2 that vibration amplitudes at the arch dam top were large as constraints were applied to arch dam parts such as dam bottom and dam shoulders which contacted the base rock, and the freedom degree was restrained, while motion on the dam top was not influenced. Hence, in comparison with other parts of the dam body, the vibration amplitude on the dam top was larger. Vibration form of the arch dam was mainly the vibration along the river direction. In comparison with the cross-river direction, rigidity in the direction along the river was small, so vibration of the dam body could more easily appear in the direction along the river. The first-order vibration mode showed an antisymmetric form with the arch dam center line as the symmetric axis. Maximum vibration amplitudes appeared on the top end of arch dam and $1 / 4$ dam sections of both sides. Vibration moved back and forth along the river direction, while motion directions were opposite. The second-order vibration mode approached a positive symmetric form. The maximum vibration amplitude appeared at the dam top center. With this part as the center, the vibration amplitude decreased gradually in different directions. The third-order vibration mode was positively symmetric. Vibration amplitudes at $1 / 4$ dam sections of both sides were large. The maximum vibration amplitude appeared at the position of the dam top close to $1 / 4$ dam section of left bank, while the motion direction of both sides was opposite to the motion direction at the dam top center. The fourth-order vibration mode was also positively symmetric. The maximum vibration amplitude appeared at the $1 / 6$ dam section and the top end of the arch dam. However, vibration amplitudes at the arch dam top were smaller than those at $1 / 6$ dam sections of both sides. For the fifthorder, sixth-order, and seventh-order vibration modes, the arch dam vibration modes under the empty-reservoir and full-reservoir working conditions showed different forms, wherein the sixth-order vibration mode at the full-reservoir state and the seventh-order vibration mode at the emptyreservoir state were similar.

\section{Dynamic Responses of Arc Dam under Earthquake}

As for the arch dam, upstream water bodies of the arch dam can be deemed as infinite water areas. Westergaard [18] researched dynamic water pressure on the rigid upright dam face. It was assumed that the upstream direction of reservoir water was infinite, the reservoir bottom was a rigid water plane, reservoir water conducted nonrotary motion with small deformation, and surface fluctuation effects were neglected. The series-form solution of the dynamic water pressure which was applied by the compressible reservoir water on the rigid upright dam face under the two-dimensional dynamic water pressure analysis model during ground horizontal SHM was solved. Meanwhile, an added mass model without conditioner of dam body deformation and reservoir water compressibility was proposed. According to the condition that the force moment of actual dynamic water pressure on the dam heel is equal to the force moment of approximate dynamic water pressure graph on the dam heel, an added mass formula was deduced as follows:

$$
b(y)=\frac{7}{8} \sqrt{h_{i} z}
$$

where, as shown in Figure 3, $b(y)$ denotes the width of added water body mass, $h_{i}$ denotes the vertical height from a waterstopping building at point $i$ to the dam site boundary line, and $z$ denotes the vertical distance between the vertical face from a point to the point and the bottom reservoir. In (1), it is assumed that reservoir water was incompressible; complicated factors such as dam body deformation are neglected, so it is simple and practical. Hence, it is widely applied in practical engineering. Till now, it is still applied in antiseismic specifications of many countries. The formula is based on various assumption conditions such as straightness of the water-meeting face of dam body, so it does not satisfy practical engineering conditions.

In 1982, Clough [19] generalized the added mass formula of Westergaard so as to make it adapted to dam faces with different shapes and river valleys with different shapes. 


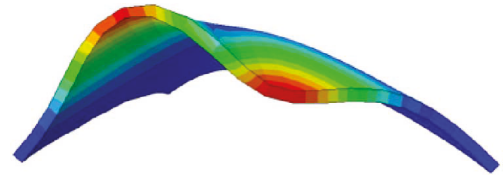

(a) First order (empty reservoir)

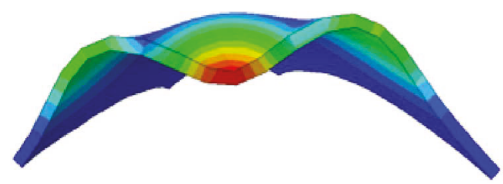

(c) Second order (empty reservoir)

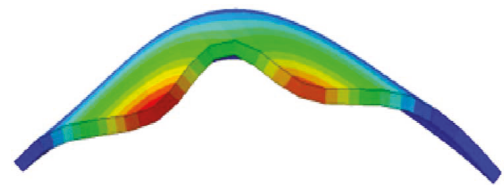

(e) Third order (empty reservoir)

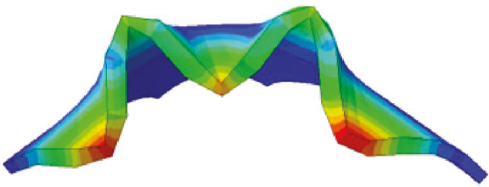

(g) Fourth order (empty reservoir)

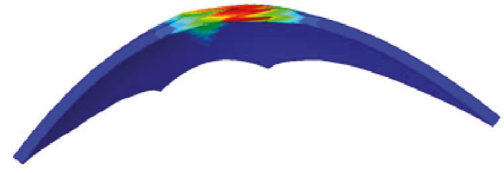

(i) Fifth order (empty reservoir)

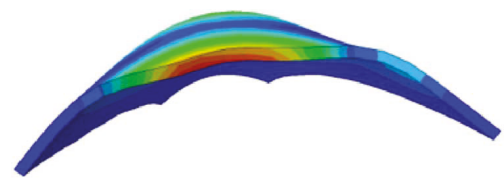

(k) Sixth order (empty reservoir)

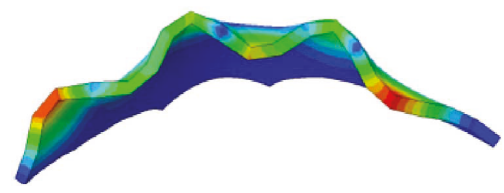

(m) Seventh order (empty reservoir)

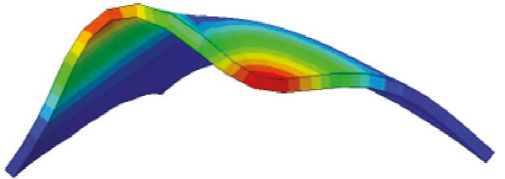

(b) First order (full reservoir)

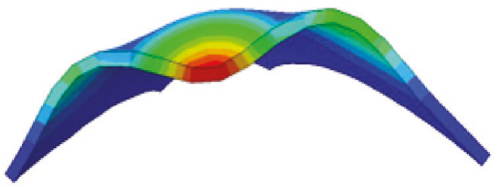

(d) Second order (full reservoir)

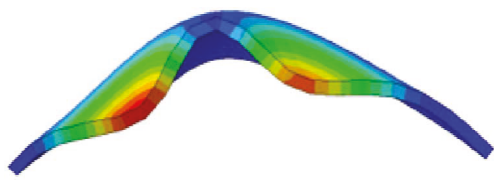

(f) Third order (full reservoir)

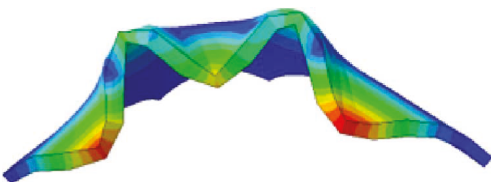

(h) Fourth order (full reservoir)

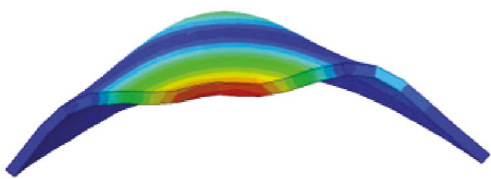

(j) Fifth order (full reservoir)

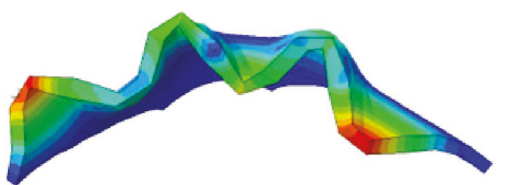

(1) Sixth order (full reservoir)

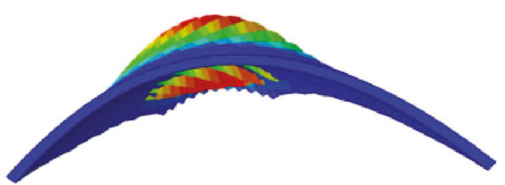

(n) Seventh order (full reservoir)

FIgURE 2: Vibration modes of arch dam under empty-reservoir and full-reservoir working conditions.
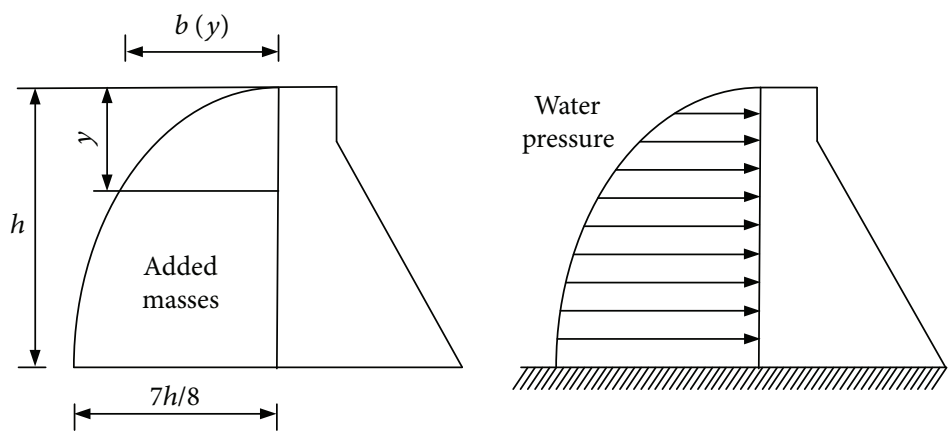

FIGURE 3: Westergaard dynamic water pressure and added mass on dam face. 


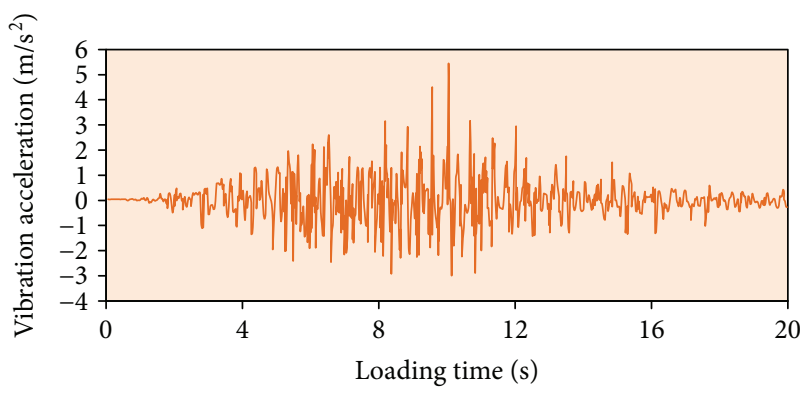

(a) Cross-river acceleration

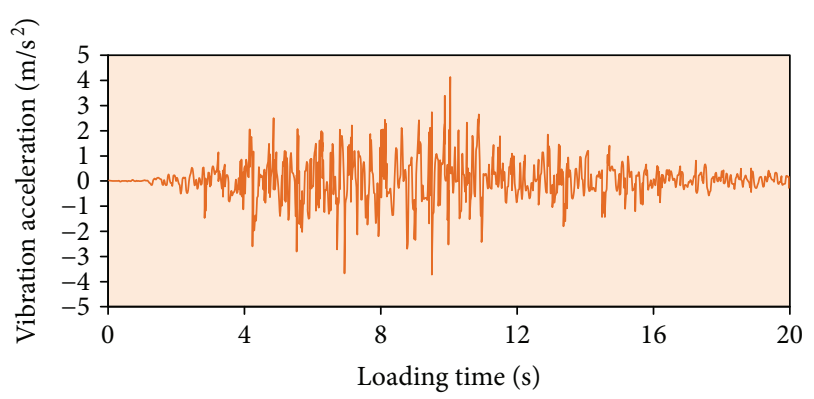

(b) Along-river acceleration

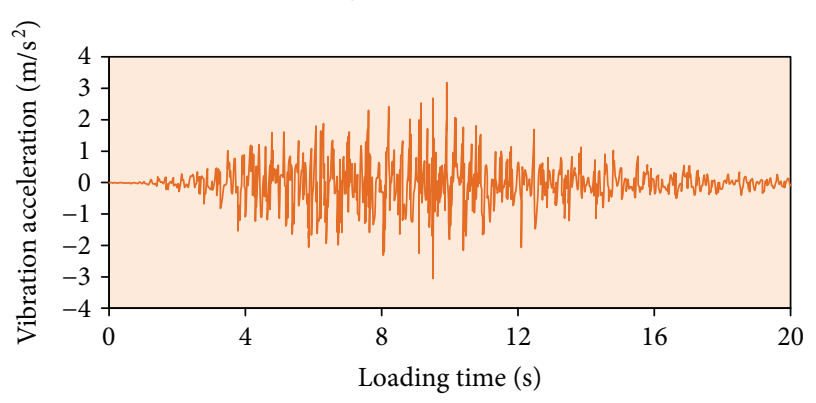

(c) Vertical acceleration

Figure 4: Time-interval acceleration of seismic waves in three directions of the arch dam.

Meanwhile, seismic accelerations in different directions could be taken into account, namely,

$$
M_{p}=\frac{7}{8} \rho A_{i} \sqrt{h_{i} z} l_{i}^{T} l_{i},
$$

where $l_{i}$ denotes the normal vector of a point $i$ on the dam face and $A_{i}$ denotes the subordinate area of this point on the dam face. Physical meanings of other symbols are ditto. The paper researches the curved-face arch dam. Hence, the water added mass formula proposed by Clough was selected for solution.

During dynamic response analysis of the arch dam, seismic waves could be input directly as seismic loads. Hence, selection of seismic waves has significant effects on accuracy of arch dam dynamic analysis. However, general dam site areas do not have existing strong earthquake records basically. Hence, existing strong earthquake records of other areas shall often be used during dynamic analysis. Through some manual processing methods, proper seismic waves could be obtained, as shown in Figure 4. It is shown in Figure 4 that the seismic acceleration in the cross-river direction had the maximum amplitude, while the vertical acceleration had the minimum amplitude. Energy of seismic waves was mainly concentrated within $8-15 \mathrm{~s}$. Around $0 \mathrm{~s}$, seismic wave accelerations in different directions tended to be roughly symmetrical.

The paper researches bearing gravity, hydrostatic pressure, and seismic loads of the arch dam. In order to present effects of several loads, displacement and stress pressure of the arch dam under gravity effect only were computed at first, as shown in Figure 5. It is shown in Figure 5 that large vibration displacement of the arch dam appeared at the 1/2 dam section. Vibration was small in connecting areas between two sides and the base rock, as motion around the arch dam was restrained by the base rock, while rigidity at the $1 / 2$ dam section was small. However, stress of the arch dam was mainly distributed at joints with the base rock, so stress concentration would be caused by constraint effects here. Displacement and stress distribution of the arch dam under gravity and hydrostatic pressure were further computed, as shown in Figure 6. Displacement and stress distribution in Figure 6 were different from Figure 5. Positions with large vibration displacement mainly appeared at the left side of $1 / 2$ dam section. Stress distribution areas were similar with those of vibration displacement. Stress concentration did not appear at joints between the arch dam and base rock. This result is enough to show that effects of hydrostatic pressure on the arch dam were obviously larger than gravity effects and could bring serious impacts on dynamic characteristics of the arch dam. Seismic loads were taken into account. Distribution of displacement and stress of the arch dam under gravity, hydrostatic pressure, and seismic loads was computed, as shown in Figure 7. It is shown in the diagram that the distribution area of vibration displacement amplitude areas was increased by seismic loads, so displacement and stress were symmetrically distributed relative to the arch dam axis. However, distribution positions of vibration displacement and stress were quite similar with Figure 6.

Above discussion and analysis indicate that, during researches of dynamic characteristics of an arch dam, comprehensive effects of gravity, hydrostatic pressure, and seismic loads shall be taken into full account; otherwise, computation results would have serious deviation. In a constitutive model of concrete plastic failure, plastic flow is irrelevant [20-23]. Hence, in order to achieve quicker convergence, the keyword UNSUMM = YES can be set in *STEP, so that matrixes would be stored asymmetrically in computation. During analysis of effects of gravity, hydrostatic pressure, and seismic loads, automatic time increment steps were used. Computation results are shown in Figures 8-10. It is shown in Figure 8 that damage just began appearing at $t=3.341 \mathrm{~s}$. It mainly appeared joints between two sides of the arch dam and the base rock. Areas with large vibration displacement were different from damaged parts as rigidity at the arch dam top was small; rigidity at joints between both sides and the base rock were large; under loads, positions with large rigidity could not start flexible vibration together with the loads. It is shown in Figure 9 that, at $t=4.721 \mathrm{~s}$, damage gradually extended to the center from 


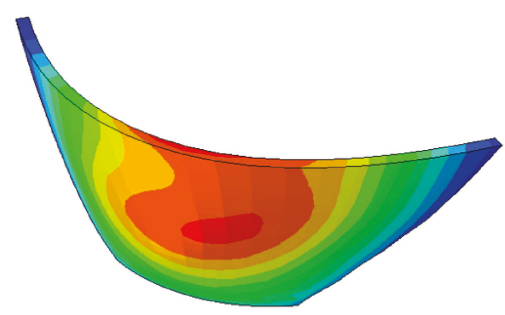

(a) Displacement

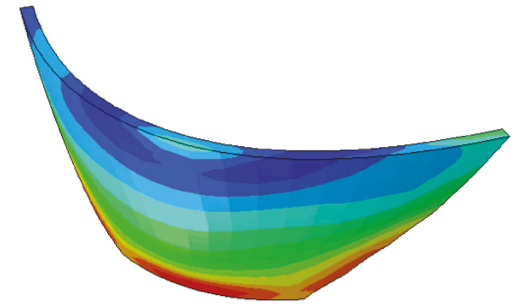

(b) Stress

FIGURE 5: Displacement and stress distribution of arch dam under self-weight.

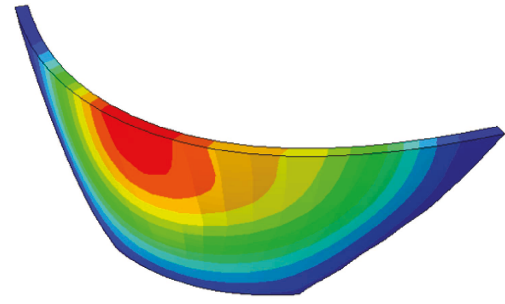

(a) Displacement

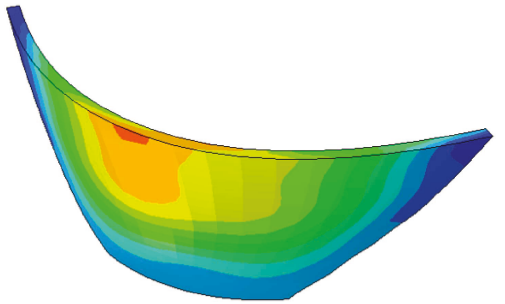

(b) Stress

FIGURE 6: Displacement and stress distribution of arch dam under self-weight and hydrostatic pressure.

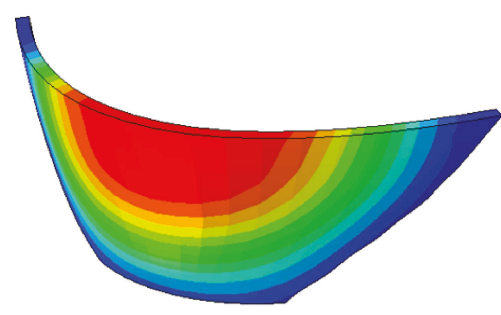

(a) Displacement

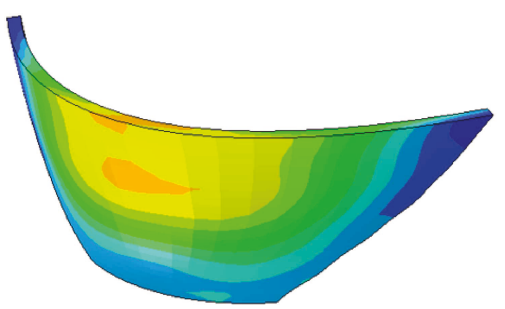

(b) Stress

FIgURE 7: Displacement and stress distribution of arch dam under seismic effect.

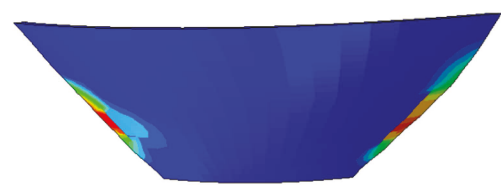

(a) Tensile damage

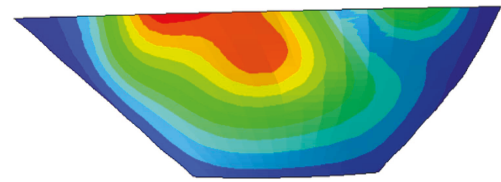

(c) Displacement

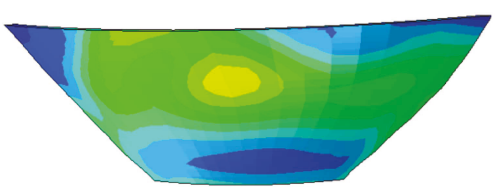

(b) Stress

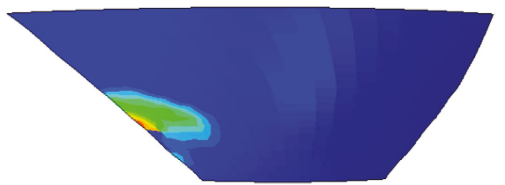

(d) Rigidity degeneration

Figure 8: Dynamic response distribution of arch dam at $t=3.341 \mathrm{~s}$.

joints between two sides of the arch dam and the base rock. With continuous increase of the acting time, damage changes of the arch dam were very small, as shown in Figure 10. This result indicates that the arch dam was basically damaged at $t=4.721 \mathrm{~s}$.

In the time-interval analysis method, in order to reflect time-interval responses of displacement and stress of the arch dam, typical points shall be selected for analysis. Displacement time-interval curves of nodes were taken as representatives for analysis of effects borne by the arch dam under seismic waves. As shown in Figure 11, point 1 is located at the right bank dam shoulder and point 2 is located at the center of arc beam top. As shown in the arc dam model, only the top of the arch dam is not constrained by the base 


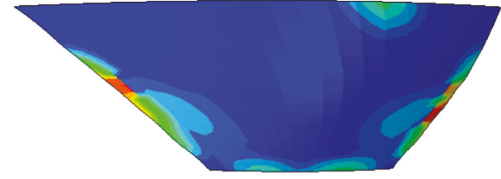

(a) Tensile damage

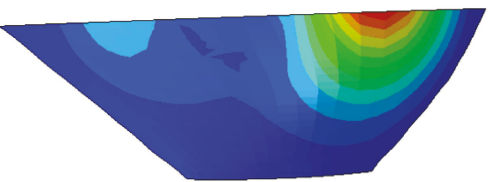

(c) Displacement

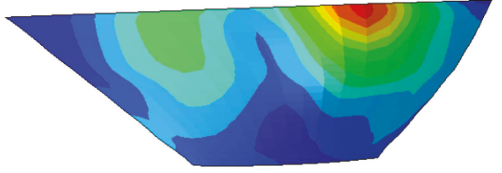

(b) Stress

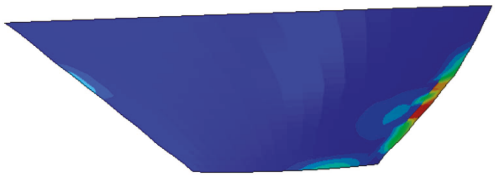

(d) Rigidity degeneration

FiguRE 9: Dynamic response distribution of arch dam at $t=4.721 \mathrm{~s}$.

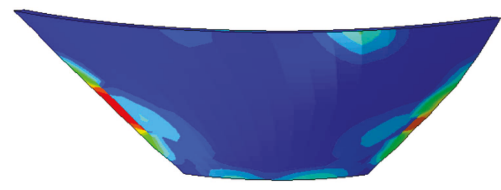

(a) Tensile damage

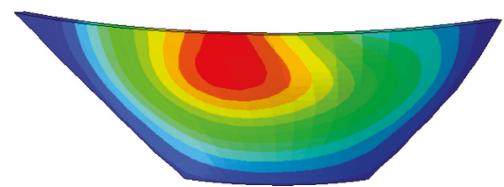

(c) Displacement

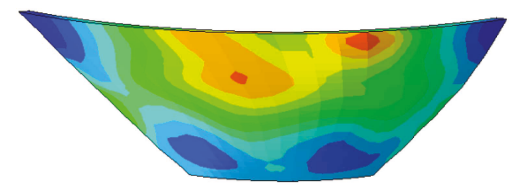

(b) Stress

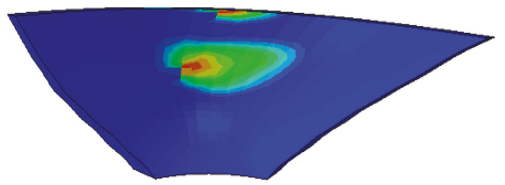

(d) Rigidity degeneration

FIGURE 10: Dynamic response distribution of arch dam at $t=6.012 \mathrm{~s}$.
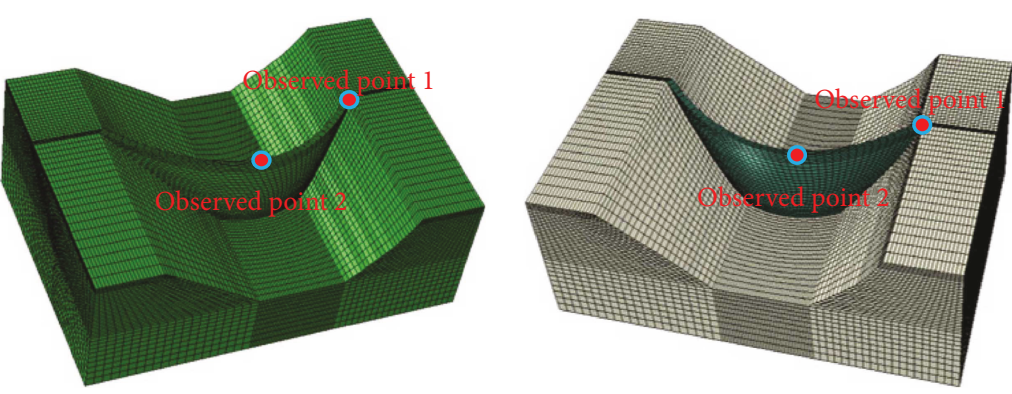

FIGURE 11: Observation points of time-interval responses of arch dam displacement.

rock. Also, in the dynamic response distribution of the arch dam, the serious responses are often distributed in the top part, while the bottom of the arch dam will have a small dynamic response. Displacement time-interval curves of points 1 and 2 in directions $\mathrm{X}, \mathrm{Y}$, and $\mathrm{Z}$ are shown in Figures 12 and 13. Through displacement time-interval curve analysis of the selected nodes, we can find that the maximum displacement of the dam body in $\mathrm{X}$ direction appeared at point 2 and at $10 \mathrm{~s}$, with the maximum value of $4.6 \mathrm{~mm}$; the maximum displacement in $\mathrm{Y}$ direction appeared at point 2 and at $9.5 \mathrm{~s}$, with the maximum value of $45.5 \mathrm{~mm}$; the maximum displacement in $\mathrm{Z}$ direction appeared at point 2 and at $10.2 \mathrm{~s}$, with the maximum value of $12.3 \mathrm{~mm}$. Displacement of the dam body mainly appeared along the river, while the maximum displacement appeared at point 2 which was located at the dam top center; in the cross- river direction, the maximum displacement of dam body also appeared at point 2 which was located at the dam top center; under seismic loads, arch dam displacement was similar with seismic waves.

Damage time-interval curves of the arch dam were extracted, as shown in Figure 14. It is shown in the diagram that, within $0-3.341 \mathrm{~s}$, the arch dam bore comprehensive effects of gravity, hydrostatic pressure, and seismic loads, but it was not damaged at all. After $3.341 \mathrm{~s}$, damage of the arch dam increased sharply by stages. At $4.721 \mathrm{~s}$, damage of the arch dam basically tended to be stable, while the arch dam was completely damaged at this moment. It can also be seen from comparison between Figures 9 and 10. Damage contours of the arch dam did not change basically. Additionally, in the time-interval acceleration of seismic waves in three directions of the arch dam, the maximum value is 


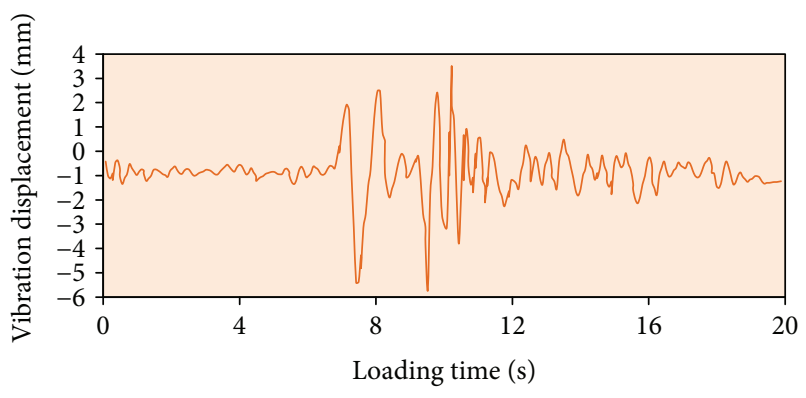

(a) Displacement time-interval curve of point 1 in direction $\mathrm{X}$

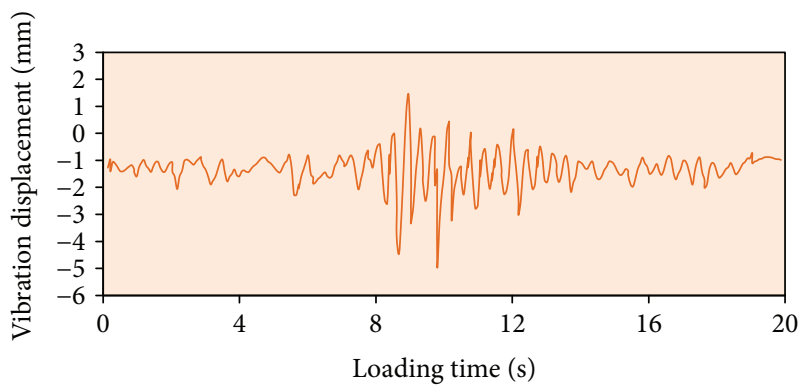

(b) Displacement time-interval curve of point 1 in direction $Y$

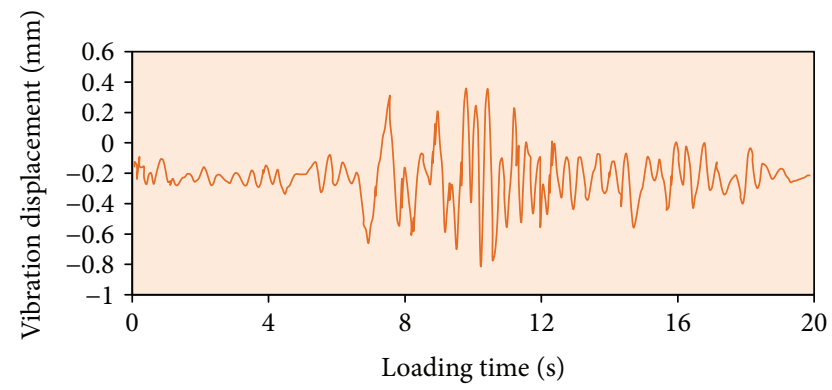

(c) Displacement time-interval curve of point 1 in direction $\mathrm{Z}$

Figure 12: Displacement time-interval curves of point 1 in directions $\mathrm{X}, \mathrm{Y}$, and $\mathrm{Z}$.

presented about $10 \mathrm{~s}$, but the maximum damage value of the arch dam is presented about $4 \mathrm{~s}$ because the seismic wave is relatively big, and the arch dam will be damaged when the seismic wave is not located at the maximum value.

\section{Improvement of Antiseismic Performance of Arc Dam}

Above discussion and analysis results indicate that antiseismic performance of the arch dam was poor, while measures should be taken for improvement. As shown in Figure 15, a layer of reinforcement was set inside the arch dam. In fact, the material of the reinforcement is steel, so the elastic modulus is $2.1 e^{11} \mathrm{~Pa}$, the density is $7800 \mathrm{~kg} / \mathrm{m}^{3}$, and the Poisson's ratio is 0.3 . The concrete is poured on both sides of the reinforcement. In the finite element model, the reinforcement and concrete were connected by conodes. As well, the finite element method was used to compute displacement and stress distribution of the reinforced arch dam under gravity and hydrostatic pressure, as shown in Figures 16 and 17. Under gravity effects, vibration displacement of the reinforced arch dam mainly appeared at the center of arch

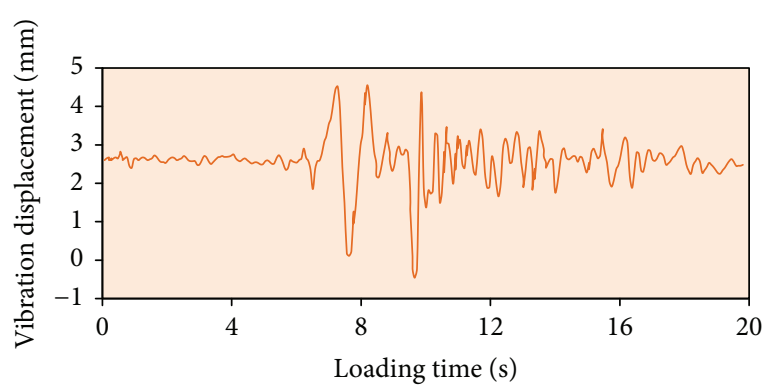

(a) Displacement time-interval curve of point 2 in direction $\mathrm{X}$

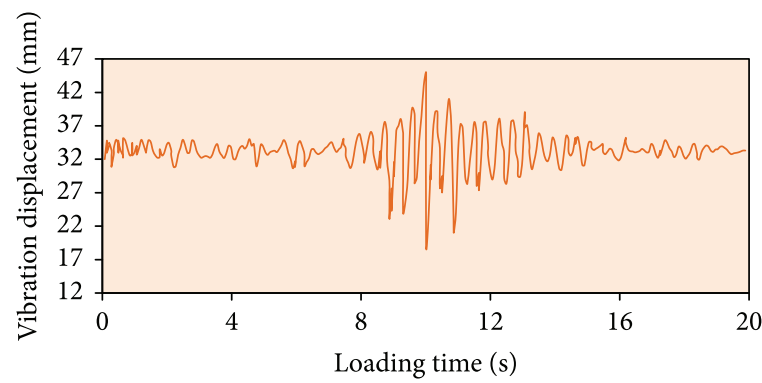

(b) Displacement time-interval curve of point 2 in direction $\mathrm{Y}$

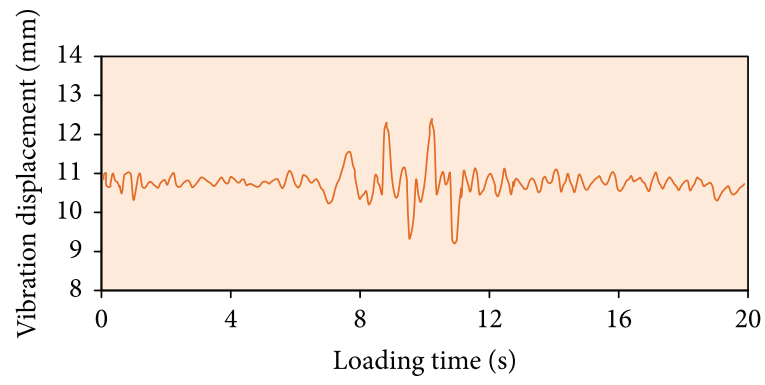

(c) Displacement time-interval curve of point 2 in direction $\mathrm{Z}$

FIgURE 13: Displacement time-interval curves of point 2 in directions $\mathrm{X}, \mathrm{Y}$, and $\mathrm{Z}$.

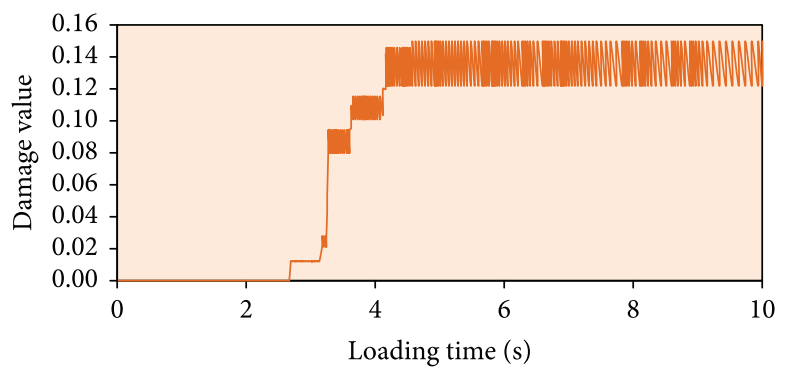

Figure 14: Damage time-interval curve at dam top.

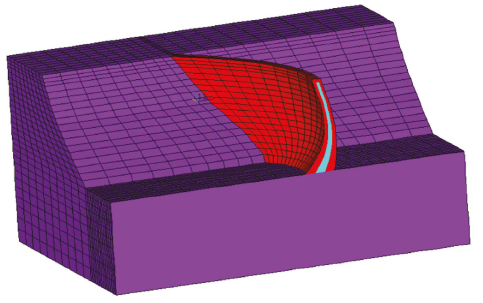

FIGURE 15: Finite element model of arch dam with reinforcement inside. 


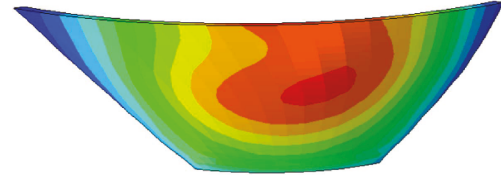

(a) Displacement

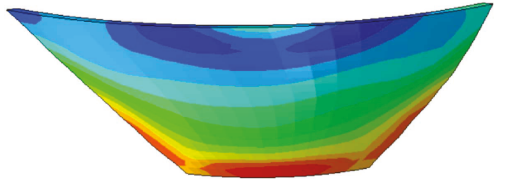

(b) Stress

FiguRE 16: Displacement and stress distribution of arch dam under gravity.

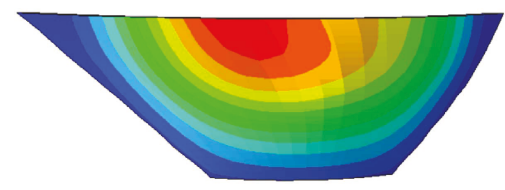

(a) Displacement

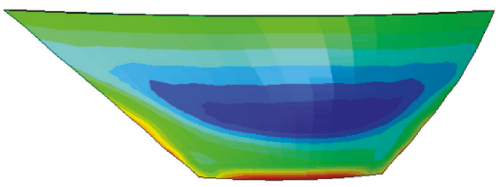

(b) Stress

FIGURE 17: Displacement and stress distribution of arch dam under gravity and hydrostatic pressure.

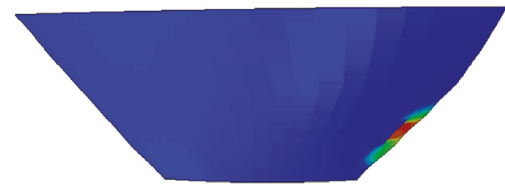

(a) Tensile damage

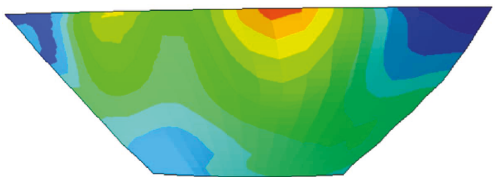

(b) Stress

Figure 18: Dynamic response distribution of arch dam at $t=2.411 \mathrm{~s}$.

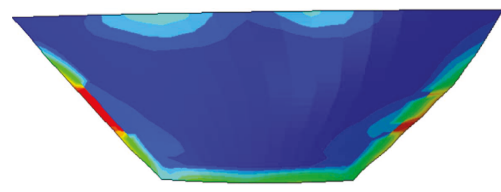

(a) Tensile damage

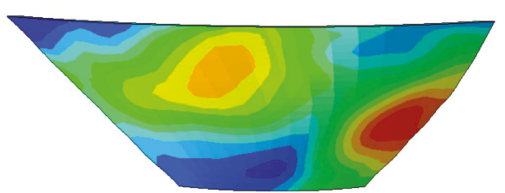

(b) Stress

Figure 19: Dynamic response distribution of arch dam at $t=5.425 \mathrm{~s}$.

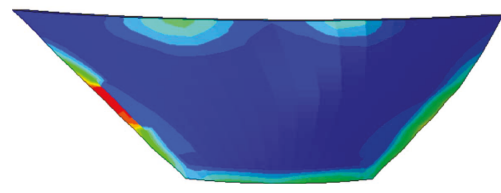

(a) Tensile damage

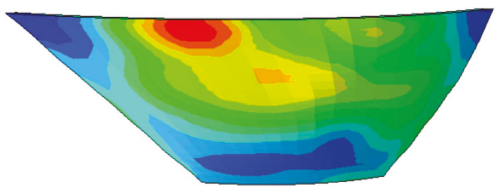

(b) Stress

Figure 20: Dynamic response distribution of arch dam at $t=8.087 \mathrm{~s}$.

dam, while stress concentration appeared joints with the base rock as constraint effect here could cause stress concentration. It is shown in Figure 17 that, after increase of the hydrostatic pressure, vibration displacement and stress distribution of the arch dam changed. However, as well, the vibration displacement mainly appeared at the arch dam center, while stress concentration appeared at joints between the arch dam and base rock. However, after application of the hydrostatic pressure, small stress on the arch dam appeared at the center area. While the small stress of the arch dam with mere consideration of gravity mainly appeared at the top.

As well, dynamic responses of the reinforced arch dam under gravity, hydrostatic pressure, and seismic loads were computed, as shown in Figures 18-20. It is shown in Figure 18 that, at $t=2.411 \mathrm{~s}$, damage just began appearing and mainly appeared at joints between the right side of the arch dam and the base rock; areas with large vibration displacement were different from damaged parts as rigidity on the arch dam top was small, rigidity at joints between both sides and the base rock was large, and positions with large rigidity could not start flexible vibration with the loads under load effects. It is shown in Figure 19 that, at $t=$ $5.425 \mathrm{~s}$, damage extended gradually to the center from joints between the right side of arch dam and the base rock. With the continuous increase of acting time, damage changes of the arch dam were very small, as shown in Figure 20. This result indicates that the arch dam was basically damaged at $t=5.425 \mathrm{~s}$. The original arch dam was thoroughly damaged at $t=4.721 \mathrm{~s}$, while the reinforced arch dam was damaged at $t=5.425 \mathrm{~s}$, indicating that the reinforcement measure proposed by the paper is effective. 


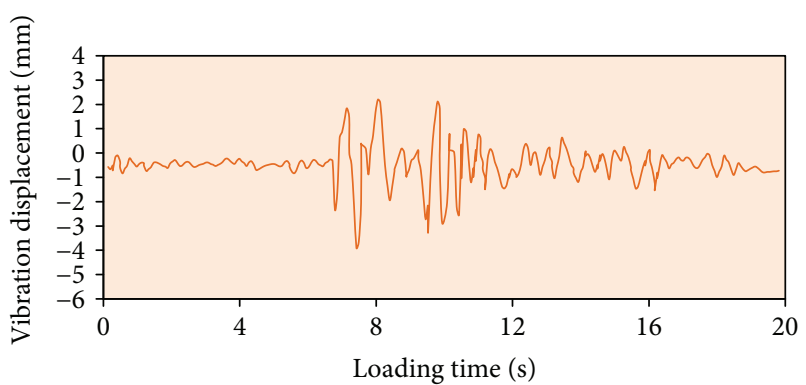

(a) Displacement time-interval curve of point 1 in direction $\mathrm{X}$

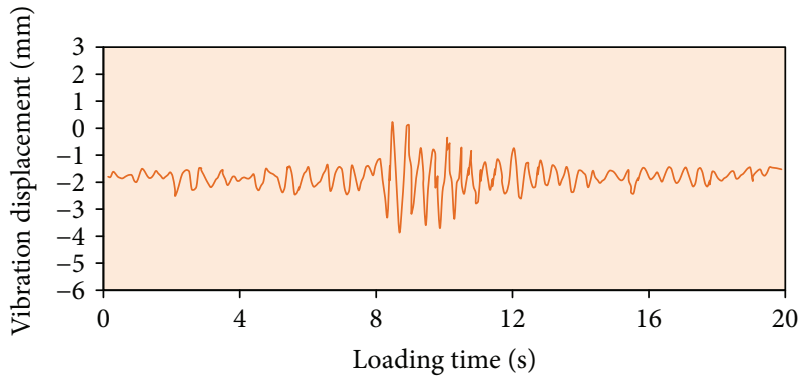

(b) Displacement time-interval curve of point 1 in direction $Y$

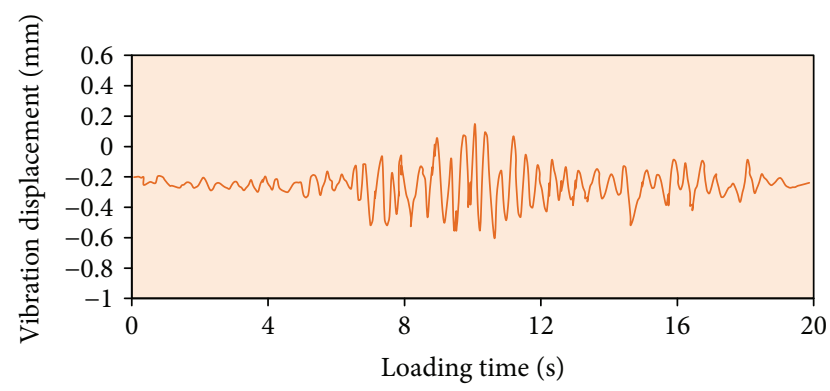

(c) Displacement time-interval curve of point 1 in direction $\mathrm{Z}$

Figure 21: Displacement time-interval curves of point 1 in directions $\mathrm{X}, \mathrm{Y}$, and $\mathrm{Z}$.

In order to further verify antiseismic performance of the reinforced arch dam, displacement time-interval curves of observation points 1 and 2 in directions $\mathrm{X}, \mathrm{Y}$, and $\mathrm{Z}$ were extracted, as shown in Figures 21 and 22. It is shown in the diagram that the maximum displacement time interval of point 1 of the reinforced arch dam in direction $\mathrm{X}$ was $2.3 \mathrm{~mm}$. The maximum displacement time interval of this point of the original arch dam was $3.6 \mathrm{~mm}$, with the relative decrease of $36.11 \%$. The maximum displacement time interval of point 1 of the reinforced arch dam in direction $\mathrm{Y}$ was $0.6 \mathrm{~mm}$. The maximum displacement time interval of this point of the original arch dam was $1.2 \mathrm{~mm}$, with the relative decrease of $50.00 \%$. The maximum displacement time interval of point 1 of the reinforced arch dam in direction $\mathrm{Z}$ was $0.15 \mathrm{~mm}$. The maximum displacement time interval of this point of the original arch dam was $0.31 \mathrm{~mm}$, with the relative decrease of $51.61 \%$. The maximum displacement time interval of point 2 of the reinforced arch dam in direction $\mathrm{X}$ was $4.1 \mathrm{~mm}$. The maximum displacement time interval of this point of the original arch dam was $4.6 \mathrm{~mm}$, with the relative decrease of $10.87 \%$. The maximum displacement time interval of point 2 of the reinforced arch dam in direction $Y$ was

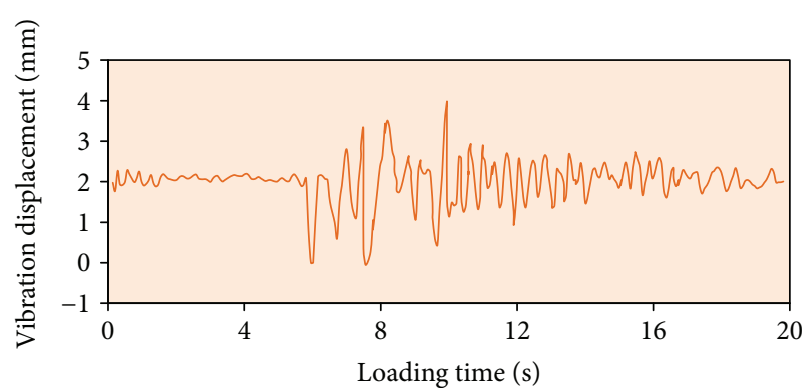

(a) Displacement time-interval curve of point 2 in direction $\mathrm{X}$

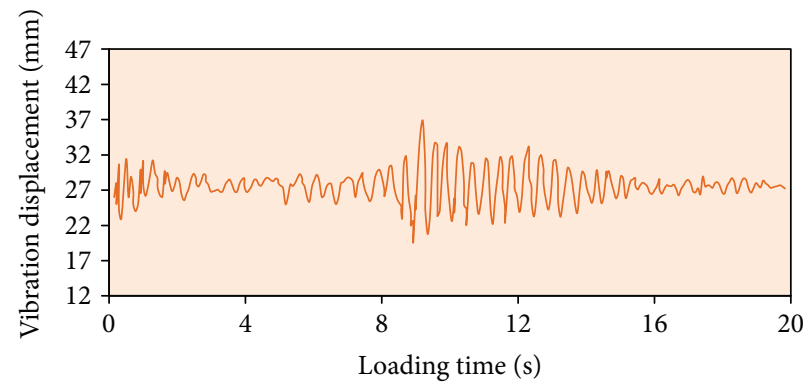

(b) Displacement time-interval curve of point 2 in direction $\mathrm{Y}$

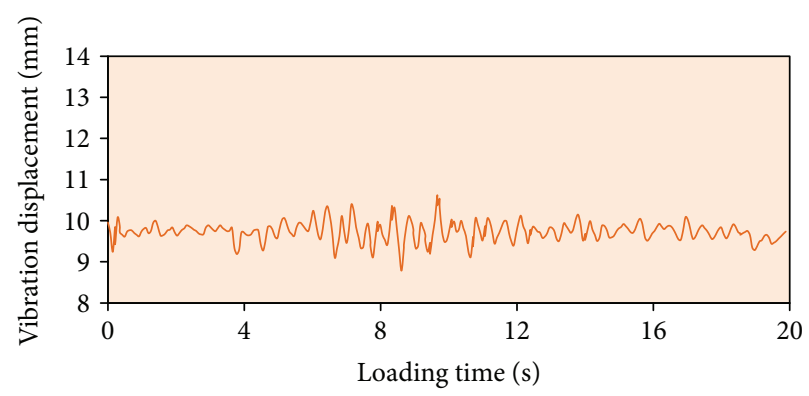

(c) Displacement time-interval curve of point 2 in direction $\mathrm{Z}$

FIgURE 22: Displacement time-interval curves of point 2 in directions $\mathrm{X}, \mathrm{Y}$, and $\mathrm{Z}$.

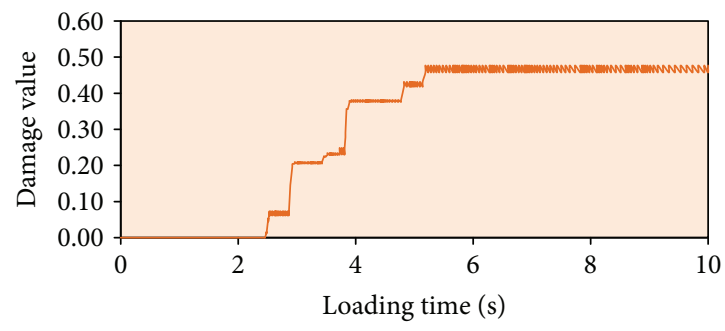

FIGURE 23: Damage time-interval curve at dam top.

$37.1 \mathrm{~mm}$. The maximum displacement time interval of this point of the original arch dam was $45.5 \mathrm{~mm}$, with the relative decrease of $18.46 \%$. The maximum displacement time interval of point 2 of the reinforced arch dam in direction $\mathrm{Z}$ was $10.6 \mathrm{~mm}$. The maximum displacement time interval of this point of the original arch dam was $12.3 \mathrm{~mm}$, with the relative decrease of $13.82 \%$. According to the compared analysis, the antiseismic performance of the arch dam has been improved obviously.

Damage time-interval curves of the reinforced arch dam were extracted, as shown in Figure 23. It is shown in the 
diagram that, within 0-2.411 s, the arch dam was not damaged at all under comprehensive effects of gravity, hydrostatic pressure, and seismic loads. After $2.411 \mathrm{~s}$, damage of the arch dam increased sharply by stages. At $5.425 \mathrm{~s}$, damage of the arch dam basically tended to be stable. The arch dam was completely damaged at this moment. It can also be seen from comparison between Figures 19 and 20. Damage contours of the damage basically had not change. In addition, damage stabilization value of the reinforced arch dam approached 0.47 , while the damage stabilization value of the original arch dam was 0.13 . Obviously, safety of the reinforced arch dam under the same loads was higher. Damage of the reinforced arch dam increased by stages. It took about $3 \mathrm{~s}$ from zero damage to damage, while the time was about only $1.3 \mathrm{~s}$ for the original arch dam. Obviously, antidamage capability of the reinforced arch dam was better. The reinforcement measure proposed by the paper is very effective.

\section{Conclusions}

(1) The natural vibration frequency of the arch dam was low; under the empty-reservoir working condition, frequencies of first 7 orders only ranged within $3.3541 \mathrm{~Hz} \sim 8.9459 \mathrm{~Hz}$; under the full-reservoir working condition, frequencies of the first 7 orders ranged within $2.4486 \mathrm{~Hz} \sim 6.9262 \mathrm{~Hz}$. At the empty-reservoir state, the natural vibration base frequency of the dam body was $3.3541 \mathrm{~Hz}$; the natural vibration base frequency under the full-reservoir state was $2.4486 \mathrm{~Hz}$, which decreased by $26.99 \%$ in comparison with the empty-reservoir state.

(2) During studying dynamic characteristics of an arch dam, comprehensive effects of gravity, hydrostatic pressure, and seismic loads shall be taken into full account; otherwise, computation results would have serious deviation.

(3) Damage stabilization value of the reinforced arch dam approached 0.47 , while the damage stabilization value of the original arch dam was 0.13 . Obviously, safety of the reinforced arch dam under the same loads was higher. Damage of the reinforced arch dam increased by stages. It took about $3 \mathrm{~s}$ from zero damage to damage, while the time was about only $1.3 \mathrm{~s}$ for the original arch dam. Obviously, antidamage capability of the reinforced arch dam was better. The reinforcement measure proposed by the paper is very effective.

(4) Arch dam is a huge and complicated hydraulic building. The process from establishment of a finite element model to the analysis is a complicated course. In particular, during analyzing dynamics of an arch dam under dynamic loads, a lot of parameters hard to quantify and uncertain factors exist, which may bring certain errors to the analysis. Hence, in order to provide more accurate reference for design and safety evaluation of the arch dam, a lot of issues including cracks, experimental validation, and improvement design should be further researched and discussed in the future.

\section{Data Availability}

The data used to support the findings of this study are available from the corresponding author upon request.

\section{Conflicts of Interest}

The authors declare that there are no conflicts of interest regarding the publication of this paper.

\section{Acknowledgments}

This work was financially supported by Academic Achievement Cultivation Project of Key Laboratory of Ministry of Education, Xihua University (SBZDPY-11-9), and Open Fund for Water Resources and Hydropower Engineering Science State Key Laboratory, Wuhan University (2011B087).

\section{References}

[1] P. Lin, W. Zhou, and H. Liu, "Experimental study on cracking, reinforcement, and overall stability of the Xiaowan super-high arch dam," Rock Mechanics and Rock Engineering, vol. 48, no. 2, pp. 819-841, 2015.

[2] J. T. Wang, D. D. Lv, F. Jin, and C. H. Zhang, "Earthquake damage analysis of arch dams considering dam-water-foundation interaction," Soil Dynamics and Earthquake Engineering, vol. 49, pp. 64-74, 2013.

[3] Y. F. Chen, J. M. Hong, H. K. Zheng, Y. Li, R. Hu, and C. B. Zhou, "Evaluation of groundwater leakage into a drainage tunnel in Jinping-I arch dam foundation in southwestern China: a case study," Rock Mechanics and Rock Engineering, vol. 49, no. 3, pp. 961-979, 2016.

[4] A. K. Chopra, "Earthquake analysis of arch dams: factors to be considered," Journal of Structural Engineering, vol. 138, no. 2, pp. 205-214, 2012.

[5] A. Bayraktar, B. Sevim, and A. Can Altunişik, "Finite element model updating effects on nonlinear seismic response of arch dam-reservoir-foundation systems," Finite Elements in Analysis and Design, vol. 47, no. 2, pp. 85-97, 2011.

[6] S. S. Li, Z. J. Liu, M. X. Jia, and W. Xie, "Effects of different foundation model on the dynamic response of arch dam," Water Power, vol. 43, no. 8, pp. 56-62, 2017.

[7] J. G. Du, G. Lin, and Z. Q. Hu, "Dynamic response analysis of high arch dams sited on inhomogeneous unbounded foundation," Chinese Journal of Rock Mechanics and Engineering, vol. 25, no. s(2), pp. 4104-4111, 2006.

[8] Y. Li and Y. T. Yang, "Analysis of arch dam dynamic and reliability based on ANSYS," Journal of Water Resources \& Water Engineering, vol. 26, no. 2, pp. 212-216, 2015.

[9] J. W. Zhang, K. L. Cao, Y. Zhao, Q. Jiang, X. L. Liu, and Z. L. Bao, "Dynamic characteristic analysis of arch dams with different forms of reservoir water coupling," Journal of Vibration, Measurement \& Diagnosis, vol. 36, no. 6, pp. 1183-1189, 2016.

[10] J. Chen, "Effects of reservoir model and reservoir depth on dynamic responses of arch dams," Journal of Earthquake Engineering and Engineering Vibration, vol. 30, no. 2, pp. 131-136, 2010. 
[11] D. Y. Li, B. Y. Zhang, and L. T. Wang, "Dynamic response analysis of Yangfanggou arch dam," Journal of Hydraulic Engineering, vol. 44, no. 12, pp. 1448-1454, 2013.

[12] M. Alembagheri and M. Ghaemian, "Damage assessment of a concrete arch dam through nonlinear incremental dynamic analysis," Soil Dynamics and Earthquake Engineering, vol. 44, pp. 127-137, 2013.

[13] B. Sevim, A. Bayraktar, A. C. Altunişik, S. Adanur, and M. Akköse, "Determination of water level effects on the dynamic characteristics of a prototype arch dam model using ambient vibration testing," Experimental Techniques, vol. 36, no. 1, pp. 72-82, 2012.

[14] B. Liu, A. J. M. Ferreira, Y. F. Xing, and A. M. A. Neves, "Analysis of functionally graded sandwich and laminated shells using a layerwise theory and a differential quadrature finite element method," Composite Structures, vol. 136, pp. 546$553,2016$.

[15] K. Cui, W.-h. Yang, and H.-y. Gou, "Experimental research and finite element analysis on the dynamic characteristics of concrete steel bridges with multi-cracks," Journal of Vibroengineering, vol. 19, no. 6, pp. 4198-4209, 2017.

[16] E. B. Chin, J. B. Lasserre, and N. Sukumar, "Modeling crack discontinuities without element-partitioning in the extended finite element method," International Journal for Numerical Methods in Engineering, vol. 110, no. 11, pp. 1021-1048, 2017.

[17] Y. Hoshi, Y. Narita, K. Honda, T. Ohtaki, I. Shitanda, and M. Itagaki, "Optimization of reference electrode position in a three-electrode cell for impedance measurements in lithiumion rechargeable battery by finite element method," Journal of Power Sources, vol. 288, pp. 168-175, 2015.

[18] H. M. Westergaard, "Water pressures on dams under earthquakes," Transactions of ASCE, vol. 98, pp. 418-433, 1933.

[19] R. W. Clough, Reservoir Interaction Effects on the Dynamic Response of Arch Dams, Water Resource and Hydropower Press of China, 1982.

[20] K. Amini, M. Jalalpour, and N. Delatte, “Advancing concrete strength prediction using non-destructive testing: development and verification of a generalizable model," Construction and Building Materials, vol. 102, pp. 762-768, 2016.

[21] S. Zhang, X. Wang, C. Wang, R. Song, and H. Y. Huo, "Compressive behavior and constitutive model for roller compacted concrete under impact loading: considering vertical stratification," Construction and Building Materials, vol. 151, pp. 428440, 2017.

[22] K. Cui and T. T. Zhao, "Unsaturated dynamic constitutive model under cyclic loading," Cluster Computing, vol. 20, no. 4, pp. 2869-2879, 2017.

[23] B. Sanz, J. Planas, and J. M. Sancho, "A method to determine the constitutive parameters of oxide in accelerated corrosion tests of reinforced concrete specimens," Cement and Concrete Research, vol. 101, pp. 68-81, 2017. 


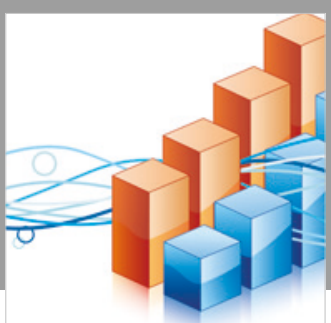

Advances in

Operations Research

\section{-n-m}
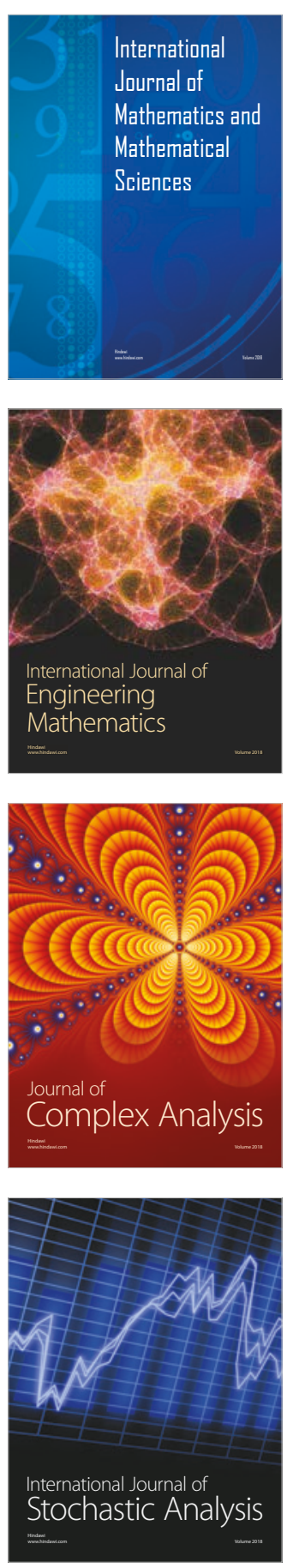
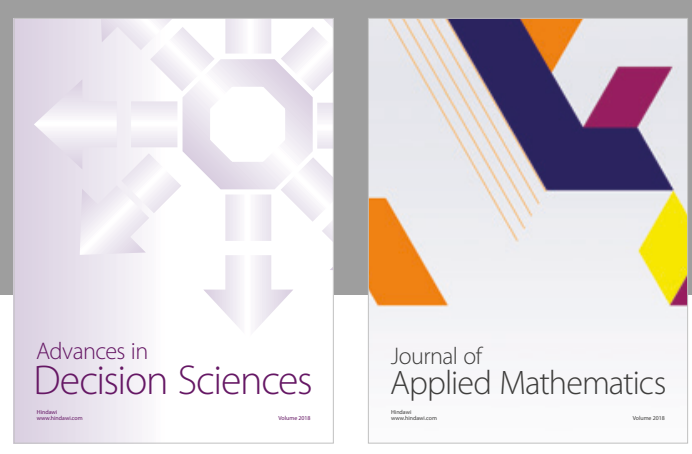

Journal of

Applied Mathematics
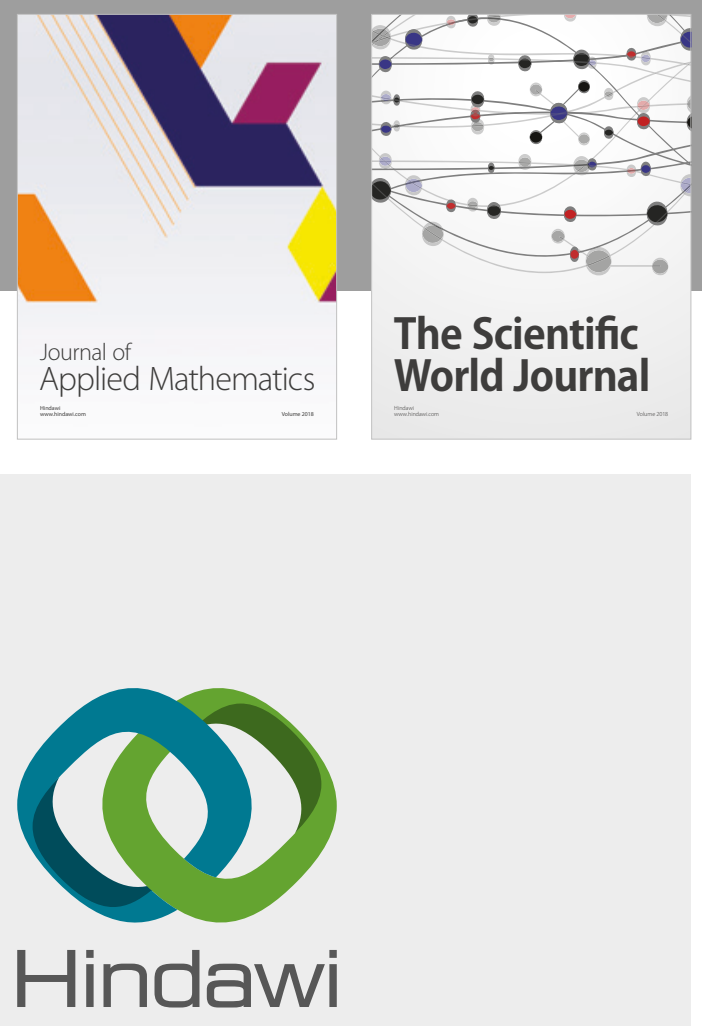

Submit your manuscripts at

www.hindawi.com

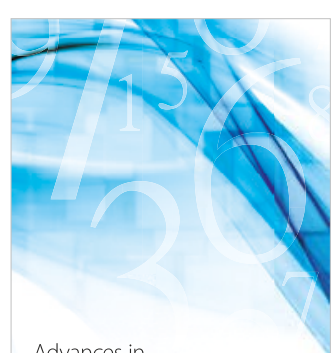

Advances in
Numerical Analysis
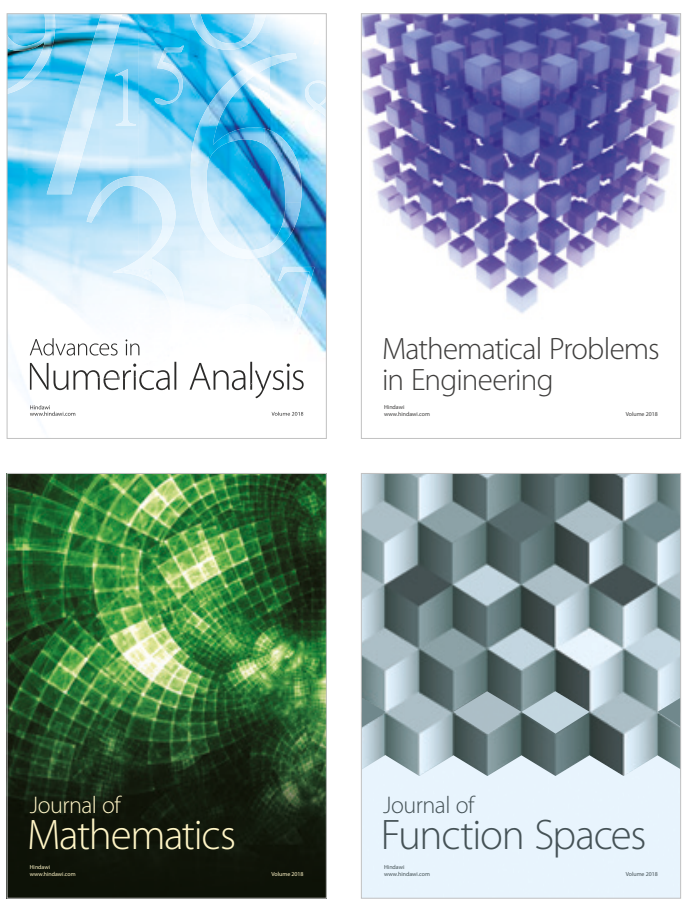

Mathematical Problems in Engineering

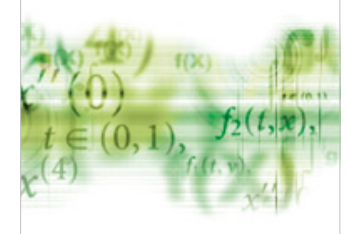

International Journal of

Differential Equations

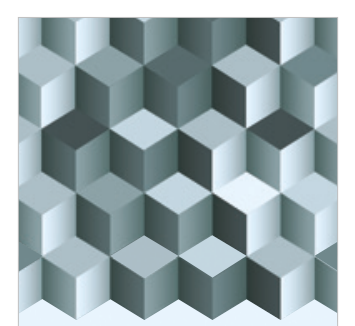

Journal of

Function Spaces
The Scientific

World Journal

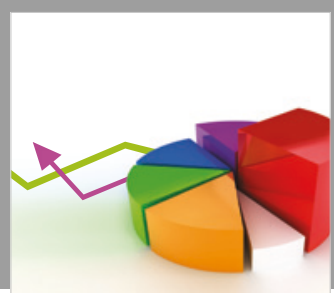

Journal of

Probability and Statistics
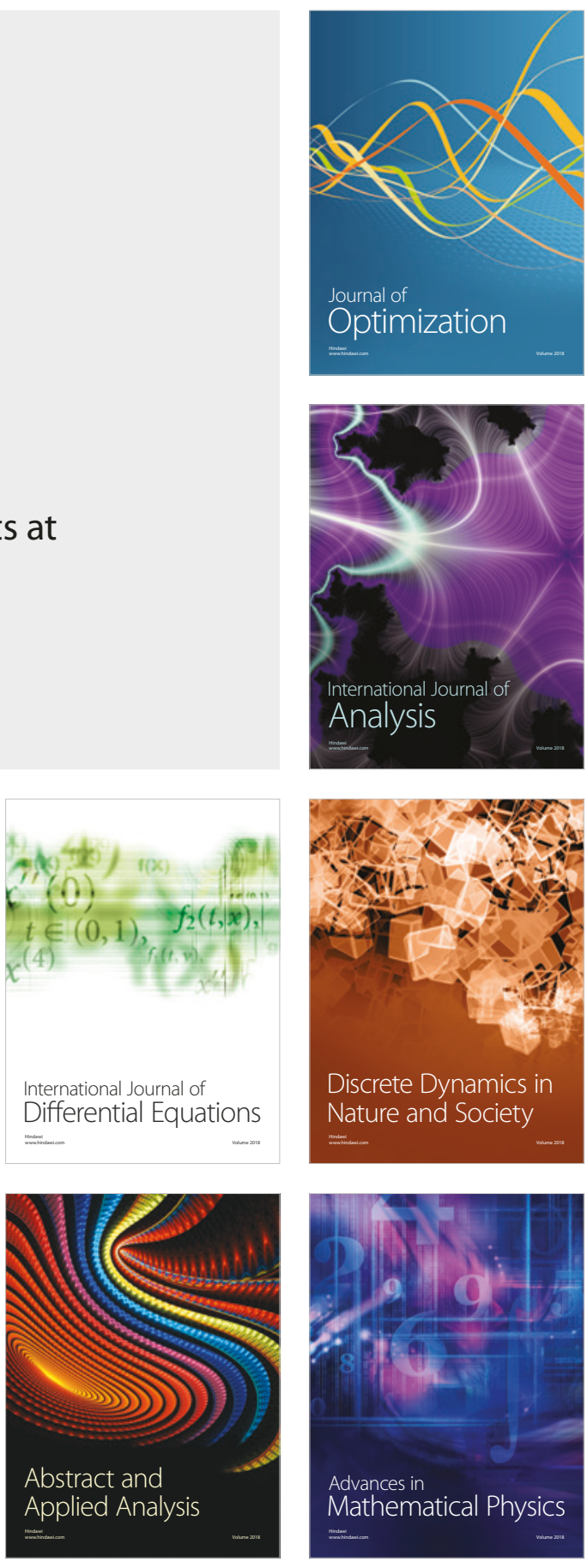